\title{
Gas phase structures and charge localization in small aluminum oxide anions: Infrared photodissociation spectroscopy and electronic structure calculations
}

Xiaowei Song, Matias R. Fagiani, Sandy Gewinner, Wieland Schöllkopf, Knut R. Asmis, Florian A. Bischoff, Fabian Berger, and Joachim Sauer

Citation: The Journal of Chemical Physics 144, 244305 (2016); doi: 10.1063/1.4954158

View online: https://doi.org/10.1063/1.4954158

View Table of Contents: http://aip.scitation.org/toc/jcp/144/24

Published by the American Institute of Physics

\section{Articles you may be interested in}

Gas phase vibrational spectroscopy of cold $\left(\mathrm{TiO}_{2}\right)_{n}^{-}(\mathrm{n}=3-8)$ clusters

The Journal of Chemical Physics 144, 124308 (2016); 10.1063/1.4942194

The vibrational spectrum of $\mathrm{FeO}_{2}{ }^{+}$isomers-Theoretical benchmark and experiment

The Journal of Chemical Physics 140, 204315 (2014); 10.1063/1.4878667

Gaussian basis sets for use in correlated molecular calculations. I. The atoms boron through neon and hydrogen

The Journal of Chemical Physics 90, 1007 (1989); 10.1063/1.456153

Gas phase infrared spectroscopy of mono- and divanadium oxide cluster cations

The Journal of Chemical Physics 120, 6461 (2004); 10.1063/1.1650833

A study of the structure and bonding of small aluminum oxide clusters by photoelectron spectroscopy: $\mathrm{Al}_{x} O_{y}^{-}$ $(\mathrm{x}=1-2, \mathrm{y}=1-5)$

The Journal of Chemical Physics 106, 1309 (1997); 10.1063/1.474085

Density-functional thermochemistry. III. The role of exact exchange

The Journal of Chemical Physics 98, 5648 (1993); 10.1063/1.464913

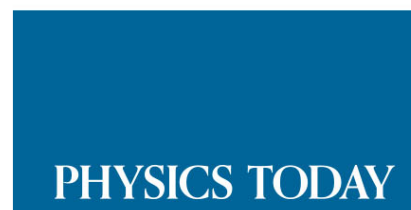

WHITEPAPERS
ADVANCED LIGHT CURE ADHESIVES

Take a closer look at what these environmentally friendly adhesive systems can do

\section{READ NOW}

PRESENTED BY

Q MASTERBOND 


\title{
Gas phase structures and charge localization in small aluminum oxide anions: Infrared photodissociation spectroscopy and electronic structure calculations
}

\author{
Xiaowei Song, ${ }^{1,2}$ Matias R. Fagiani, ${ }^{1,2}$ Sandy Gewinner, ${ }^{1}$ Wieland Schöllkopf, ${ }^{1}$ \\ Knut R. Asmis, ${ }^{2, a)}$ Florian A. Bischoff,, ${ }^{3}$ Fabian Berger, ${ }^{3}$ and Joachim Sauer,a) \\ ${ }^{1}$ Fritz-Haber-Institut der Max-Planck-Gesellschaft, Faradayweg 4-6, D-14195 Berlin, Germany \\ ${ }^{2}$ Wilhelm-Ostwald-Institut für Physikalische und Theoretische Chemie, Universität Leipzig, \\ Linnéstrasse 2, D-04103 Leipzig, Germany \\ ${ }^{3}$ Institut für Chemie, Humboldt-Universität zu Berlin, Unter den Linden 6, D-10099 Berlin, Germany
}

(Received 8 April 2016; accepted 6 June 2016; published online 27 June 2016)

\begin{abstract}
We use cryogenic ion trap vibrational spectroscopy in combination with quantum chemical calculations to study the structure of mono- and dialuminum oxide anions. The infrared photodissociation spectra of $\mathrm{D}_{2}$-tagged $\mathrm{AlO}_{1-4}{ }^{-}$and $\mathrm{Al}_{2} \mathrm{O}_{3-6}{ }^{-}$are measured in the region from 400 to $1200 \mathrm{~cm}^{-1}$. Structures are assigned based on a comparison to simulated harmonic and anharmonic IR spectra derived from electronic structure calculations. The monoaluminum anions contain an even number of electrons and exhibit an electronic closed-shell ground state. The $\mathrm{Al}_{2} \mathrm{O}_{3-6}{ }^{-}$anions are oxygen-centered radicals. As a result of a delicate balance between localization and delocalization of the unpaired electron, only the BHLYP functional is able to qualitatively describe the observed IR spectra of all species with the exception of $\mathrm{AlO}_{3}{ }^{-}$. Terminal $\mathrm{Al}-\mathrm{O}$ stretching modes are found between 1140 and $960 \mathrm{~cm}^{-1}$. Superoxo and peroxo stretching modes are found at higher $\left(1120-1010 \mathrm{~cm}^{-1}\right)$ and lower energies (850-570 $\mathrm{cm}^{-1}$ ), respectively. Four modes in-between 910 and $530 \mathrm{~cm}^{-1}$ represent the IR fingerprint of the common structural motif of dialuminum oxide anions, an asymmetric four-member $\mathrm{Al}-(\mathrm{O})_{2}-\mathrm{Al}$ ring. Published by AIP Publishing. [http://dx.doi.org/10.1063/1.4954158]
\end{abstract}

\section{INTRODUCTION}

Aluminum oxides are widely used as ceramics, coatings, abrasives, adsorbents as well as components of solid catalysts. ${ }^{1}$ For such complex materials, it remains difficult to characterize or predict the molecular scale properties and structures with atomic resolution. Gas-phase clusters, in contrast, are amenable to highly sensitive and selective experimental techniques as well as higher level computational methods. Experiments on these model systems thus provide insight into structure-reactivity correlations as well as the transition from molecular to condensed phase properties. ${ }^{2-4}$ Small aluminum oxide cluster cations ${ }^{5,6}$ and anions ${ }^{7}$ containing oxygen-centered radicals have raised interest recently as models for understanding water chemisorption and $\mathrm{C}-\mathrm{H}$ bond activation. There is also an astrochemical interest in the role that small aluminum oxide clusters play in the formation of circumstellar corundum $\left(\mathrm{Al}_{2} \mathrm{O}_{3}\right)$ grains. ${ }^{8}$

In the present study, we use cryogenic ion trap vibrational spectroscopy of messenger-tagged, mass-selected anions in combination with density functional theory (DFT) to examine the geometric structure of $\mathrm{AlO}_{1-4}{ }^{-}$and $\mathrm{Al}_{2} \mathrm{O}_{3-6}{ }^{-}$ions formed by sputtering of elemental aluminum in the presence of oxygen. We are particularly interested in the identification of reactive oxygen species like $\mathrm{O}_{2}{ }^{-} \cdot$ (superoxo), $\mathrm{O}_{2}{ }^{2-}$ (peroxo), and $\mathrm{O}^{-}$. (atomic oxygen radicals). The computed structures of the

\footnotetext{
a) Authors to whom correspondence should be addressed. Electronic addresses: knut.asmis@uni-leipzig.de and js@chemie.hu-berlin.de.
}

aluminum oxide clusters containing oxygen-centered radicals sensitively depend on the amount of exact exchange mixed into the exchange-correlation functional. Moreover, anharmonic effects, like Fermi resonances, prove to be important for explaining the experimental IR spectra.

Previous mass spectrometric investigations on gas phase aluminum oxide cluster ions have focused on their reactivity towards water, ${ }^{6,9}$ carbon monoxide, ${ }^{10}$ ammonia, ${ }^{11}$ methane,,${ }^{5,6}$ and larger alkanes. ${ }^{7}$ The smaller anions show a variety of reactions, but react more selectively than the corresponding cations. The electronically closed-shell $\mathrm{AlO}_{2}{ }^{-}$ion readily adsorbs two water molecules forming $\mathrm{Al}(\mathrm{OH})_{4}{ }^{-}$in a barrierless reaction. ${ }^{9} \mathrm{Al}_{2} \mathrm{O}_{3}{ }^{-}$and $\mathrm{Al}_{2} \mathrm{O}_{4}{ }^{-}$react with $\mathrm{CO}$ under atomic oxygen loss, suggesting the formation of $\mathrm{CO}_{2} \cdot{ }^{10} \mathrm{In}$ $\mathrm{Al}_{2} \mathrm{O}_{4}{ }^{-}$and $\mathrm{Al}_{2} \mathrm{O}_{6}{ }^{-}$, the atomic oxygen radical is predicted to be the active site for hydrogen atom abstraction from $n$-butane. ${ }^{7}$ Mass spectrometry has also been used to determine ionization energies by the way of bracketing experiments. ${ }^{12}$

Less is known about the vibrational spectroscopy of small aluminum oxide clusters. Matrix isolation IR spectroscopy has been used to study neutral clusters up to $\mathrm{AlO}_{6}$ and $\mathrm{Al}_{2} \mathrm{O}_{3}$. ${ }^{13-16}$ Aluminum oxide anions up to $\mathrm{Al}_{7} \mathrm{O}_{5}{ }^{-}$have been studied using anion photoelectron (APE) spectroscopy. ${ }^{17-21}$ The APE spectra of the smaller anions are vibrationally resolved, and when combined with electronic structure calculations, they allowed identifying an $\mathrm{Al}-(\mathrm{O})_{2}-\mathrm{Al}$ rhombus as a common structural motif of small neutral and anionic dinuclear aluminum oxides. ${ }^{18}$ Recently, vibrational and rotational molecular constants of $\mathrm{AlO}^{-}$were determined by means of autodetachment spec- 
troscopy. ${ }^{22}$ Detailed structural information on gas phase clusters can be obtained from infrared photodissociation (IRPD) spectroscopy, but until now IRPD spectra have only been reported for the aluminum oxide cations $\left[\left(\mathrm{Al}_{2} \mathrm{O}_{3}\right)_{1-4}(\mathrm{AlO})\right]^{+} .{ }^{23}$

Electronic structure studies on smaller aluminum oxides containing up to two $\mathrm{Al}$ atoms have focused mainly on neutral ${ }^{24-34}$ and to a lesser extent on anionic ${ }^{7,26,27,35-37}$ clusters. For $\mathrm{AlO}^{-}, \mathrm{AlO}_{2}^{-}$, and $\mathrm{AlO}_{4}^{-}$, closed-shell electronic ground states of ${ }^{1} \Sigma^{+}\left(C_{\infty \mathrm{v}}\right),{ }^{1} \Sigma_{\mathrm{g}}\left(D_{\infty \mathrm{h}}\right)$, and ${ }^{1} \mathrm{~A}_{1}\left(D_{2 \mathrm{~d}}\right)$ symmetry, respectively, have been predicted. ${ }^{26,27,36}$ Dialuminum oxide anions, $\mathrm{Al}_{2} \mathrm{O}_{n}{ }^{-}$, contain an uneven number of electrons and, for $n=2-6$, are characterized by a rhombic $\mathrm{Al}-(\mathrm{O})_{2}-\mathrm{Al}$ structural motif. ${ }^{7,35}$ The unpaired electron is found to be localized on one of the two terminal O-atoms in $\mathrm{Al}_{2} \mathrm{O}_{4}{ }^{-}\left(C_{2 \mathrm{v}}\right.$ structure), while in $\mathrm{Al}_{2} \mathrm{O}_{6}{ }^{-}$it is delocalized equally over the two terminal $\eta^{2}-\mathrm{O}_{2}$ groups $\left(D_{2 \mathrm{~h}}\right.$ structure $){ }^{7}$

\section{EXPERIMENTAL METHODS}

Infrared photodissociation experiments are conducted on an ion trap tandem mass spectrometer described elsewhere. ${ }^{38}$ Briefly, aluminum oxide anions are generated using a magnetron sputtering source ${ }^{39}$ Compared to more commonly used laser ablation sources, this source often yields higher ion signals for smaller metal oxide ions ( $\lesssim 10$ atoms). Continuous flows of $\mathrm{Ar}$ and $\mathrm{O}_{2}$ buffer gases are injected in front of the Al-sputtering target. He gas is introduced from the back of the sputtering chamber. The partial pressures inside the sputtering chamber are controlled individually by mass-flow controllers and allow optimizing the cluster composition and size distribution (see Fig. $\mathrm{S} 1$ in the supplementary material ${ }^{40}$ for a typical quadrupole mass spectrum). Typically, the $\mathrm{O}_{2}$ to Ar flow-ratio is below $10 \%$ and the total flow results in a pressure up to $10^{-3}$ mbar in the source chamber. Clusters nucleate and grow in a cooled aggregation chamber held at temperatures between 100 and $200 \mathrm{~K}$. The distance between the sputter head and the source chamber nozzle $(10-25 \mathrm{~cm})$ is optimized for best signal. The cluster beam is collimated using a $4 \mathrm{~mm}$ diameter skimmer. Subsequently, negative ions are compressed in phase using a radio-frequency (RF) decapole ion-guide filled with $\mathrm{He}$ as buffer gas and mass-selected using a quadrupole mass-filter. Mass-selected anions are deflected by $90^{\circ}$ and focused into a RF linear ring-electrode ion-trap held at cryogenic temperatures (15-19 K) and continuously filled with $\mathrm{D}_{2}$ gas. Trapped ions are accumulated and internally cooled by collisions with the $\mathrm{D}_{2}$ gas. Aluminum oxide anions are messenger-tagged with $\mathrm{D}_{2}$ via three-body collisions: $\mathrm{Al}_{1,2} \mathrm{O}_{n}{ }^{-}+2 \mathrm{D}_{2} \rightarrow \mathrm{Al}_{1,2} \mathrm{O}_{n}{ }^{-} \cdot \mathrm{D}_{2}+\mathrm{D}_{2}$. After an ion trap fill time of $199 \mathrm{~ms}$, all ions are extracted from the ion trap and are focused in the center of the extraction region of a timeof-flight (TOF) mass spectrometer. There they are irradiated by an intense and wavelength-tunable IR laser pulse. When resonant with a vibrational transition, parent ions absorb a photon and eventually lose one or more messenger molecules via intramolecular vibrational predissociation.

The intense and tunable IR pulses are generated by the Fritz-Haber-Institute free-electron laser (FHI FEL).$^{41}$ The wavelength of the IR radiation is tuned from 8 to $25 \mu \mathrm{m}$ with a bandwidth of ca. $0.2 \%$ root-mean-square (rms) of the central wavelength and pulse energies of $\sim 0.5-14 \mathrm{~mJ}$. IR spectra are recorded by averaging over 60 TOF mass spectra per wavelength step. The intensities are normalized to the total number of parent and fragment ions, to account for fluctuations in the total ion signal. Typically, a distribution of $\left(\mathrm{D}_{2}\right)_{m}$-tagged anions, peaking at $m=1$ and extending up to $m=4$, were produced in the ion trap. However, the differences between the action spectra of anions with a single $(m=1)$ and with more than one tag $(m>1)$ were negligible (see Fig. S2 in the supplementary material ${ }^{40}$ ) and therefore the ion yields of all tagged anions were summed up for determining the parent ion yield. The IRPD cross section $\sigma$ is determined as described previously. ${ }^{42}$

\section{COMPUTATIONAL METHODS}

For DFT structure prediction, the potential energy surface (PES) is searched first for the global minimum structures with a genetic algorithm ${ }^{43,44}$ using the BP86 functional ${ }^{45,46}$ together with the split-valence polarized basis set $\mathrm{SVP}^{47}$ (denoted $\mathrm{BP} 86 / \mathrm{SVP})$. The genetic algorithm run is repeated three times for 500 structures, after which convergence is checked. Then, the ten lowest energy structures of the GA run are refined using the $\mathrm{B}^{2} \mathrm{LYP}^{48}$ functional with the TZVPP ${ }^{47}$ basis set (Al: 5s5p3d1f, O: 5s3p2d1f). These basis sets, denoted "def2" in the Turbomole library, ${ }^{49}$ are sufficiently diffuse and, hence, adequate for a study on metal oxide anions. Finally, the structures are reoptimized using BHLYP $^{50} /$ TZVPP which includes 50\% Fock exchange in the exchange-correlation functional. For the smaller $\mathrm{AlO}_{n}{ }^{-}$systems, the coupled cluster singles and doubles with perturbative triples method $\operatorname{CCSD}(\mathrm{T})$ (see Ref. 51 and references therein) with the aug-ccpwCVTZ ${ }^{52}$ basis set and frozen core orbitals are also applied. Closed-shell anions were computed in the spin-restricted formalism of the respective theories, open-shell species in the spin-unrestricted formalism (DFT) and ROHF/UCCSD(T) formalism $(\operatorname{CCSD}(\mathrm{T}))$. The dodo program ${ }^{53}$ is used for the genetic algorithm.

Unless explicitly stated otherwise, IR spectra are computed within the double harmonic approximation. Anharmonic corrections to the vibrational energies including Fermi resonances were computed as implemented in Gaussian $09 .{ }^{54}$ Simulated harmonic spectra are derived from computed stick spectra and convoluted with a $10 \mathrm{~cm}^{-1}$ full width at half maximum (FWHM) Gaussian line shape function to effectively account for rotational band contours and the spectral width of the laser pulse.

Electronic structure calculations are performed using the following program packages: MOLPRO 2012 (CoupledCluster), ${ }^{55}$ Turbomole (DFT structure optimization and harmonic frequencies), ${ }^{49}$ and Gaussian 09 (DFT anharmonicities).$^{56}$ Total energies and $\mathrm{x}, \mathrm{y}, \mathrm{z}$ coordinates for the BHLYPoptimized structures are given in the supplementary material. ${ }^{40}$

\section{RESULTS AND DISCUSSION}

\section{A. Experimental results}

IRPD spectra of $\mathrm{D}_{2}$-tagged $\mathrm{AlO}_{1-4}{ }^{-}$and $\mathrm{Al}_{2} \mathrm{O}_{3-6}{ }^{-}$anions, measured in the spectral range from 400 to $1200 \mathrm{~cm}^{-1}$ 

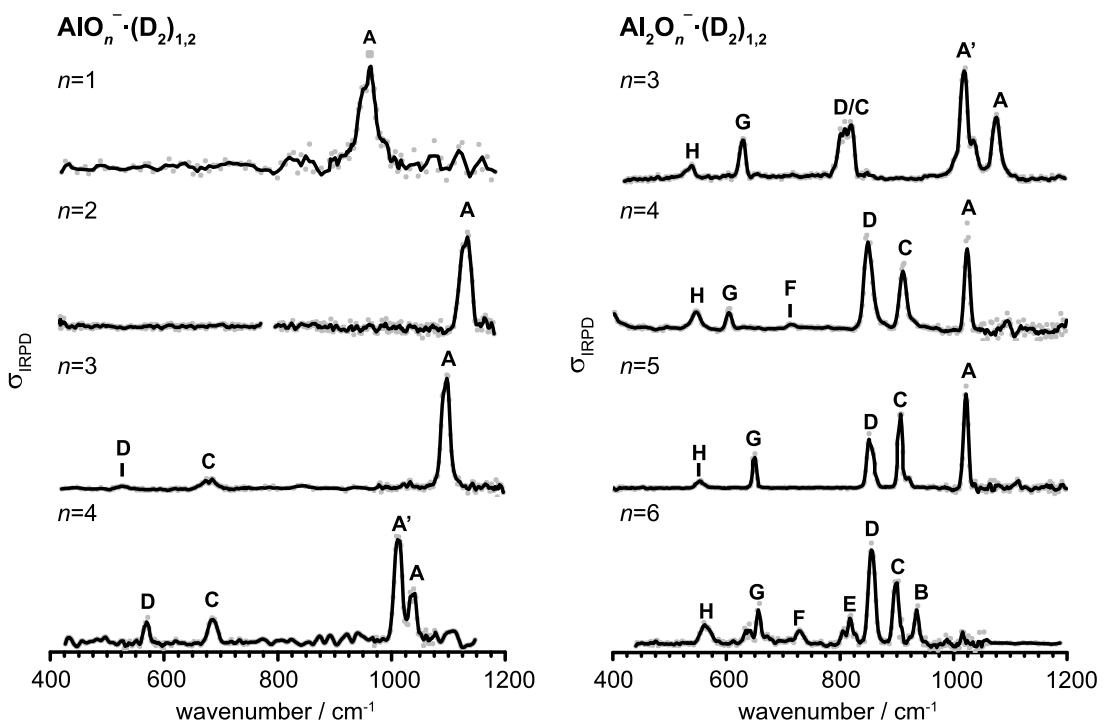

FIG. 1. IRPD spectra of $\mathrm{D}_{2}$-tagged $\mathrm{AlO}_{1-4}{ }^{-}$(left) and $\mathrm{Al}_{2} \mathrm{O}_{3-6}{ }^{-}$(right) in the spectral range from 400 to $1200 \mathrm{~cm}^{-1}$. The raw data (gray dots) and the three point adjacent-averaged trace (solid line) are plotted. Spectral features are labeled with capital letters. See Tables I and II for band positions and assignments.

and monitoring the $\mathrm{D}_{2}$ loss channels, are shown in Fig. 1. Spectral features are labeled with capital letters from A-H. Experimental band positions are summarized in Tables I and II.

\section{Monoaluminum oxide anions}

The IRPD spectrum of $\mathrm{D}_{2}$-tagged $\mathrm{AlO}^{-}$exhibits a single band, labeled $\mathbf{A}$ in Fig. 1, with a FWHM of $31 \mathrm{~cm}^{-1}$ and a rotational envelope characteristic of a linear rotor. Simulation of the rotational band contour yields a band origin of $957 \mathrm{~cm}^{-1}$ and rotational temperature of $\sim 50 \mathrm{~K}$. This band corresponds to excitation of the Al-O stretching fundamental $(v)$, in agreement with the value of $953.7 \mathrm{~cm}^{-1}$ for bare $\mathrm{AlO}^{-}$in its ${ }^{1} \Sigma^{+}$ground state determined from autodetachment spectroscopy. ${ }^{22}$ In the isoelectronic $\mathrm{SiO}$ $\left({ }^{1} \Sigma^{+}\right)$this band is observed $225 \mathrm{~cm}^{-1}$ higher in energy at $1182 \mathrm{~cm}^{-1}$. $^{57}$

The experimental IRPD spectrum of $\mathrm{D}_{2}$-tagged $\mathrm{AlO}_{2}{ }^{-}$ exhibits a single band at $1134 \mathrm{~cm}^{-1}$ (A), blue-shifted by
$177 \mathrm{~cm}^{-1}$ with respect to band $\mathbf{A}$ in the $\mathrm{AlO}^{-}$spectrum. This blue shift is comparable to that observed in the IR spectra of $\mathrm{SiO}_{2}$ (versus $\mathrm{SiO}$ ) of $198 \mathrm{~cm}^{-1}$, where the band at $1380 \mathrm{~cm}^{-1}$ corresponds to the antisymmetric stretch fundamental $v_{\mathrm{AS}}$ of linear silicon dioxide. ${ }^{57}$ Hence, band $\mathbf{A}$ is assigned to the $v_{\mathrm{AS}}$ mode of a linear $\mathrm{O}-\mathrm{Al}-\mathrm{O}$ structure, similar to the ground state structures reported for the analog group III oxides $\mathrm{BO}_{2}{ }^{-}$ and $\mathrm{GaO}_{2}{ }^{-58,59} \mathrm{~A}$ linear structure was also derived from APE spectra, which reveal the IR-inactive symmetric stretching mode in the form of a hot band at $680 \pm 60 \mathrm{~cm}^{-1} \cdot{ }^{17}$

The IRPD spectrum of $\mathrm{D}_{2}$-tagged $\mathrm{AlO}_{3}{ }^{-}$looks similar to that of $\mathrm{AlO}_{2}{ }^{-}$in that it is also dominated by an intense band at high energies $\left(\mathbf{A}, 1098 \mathrm{~cm}^{-1}\right)$, indicating the presence of terminal metal-oxo bonds. In addition, two weaker bands are observed at lower energies at $\sim 680$ (C) and $526 \mathrm{~cm}^{-1}$ (D). The isoelectronic silicon trioxide exhibits a closed-shell singlet ground state with a planar $C_{2 \mathrm{v}}$ structure that contains a strained $\mathrm{SiO}_{2}$ ring. ${ }^{60,61}$ The IR spectrum of $\mathrm{SiO}_{3}$ is characterized by a dominant peak at high energies $\left(1364 \mathrm{~cm}^{-1}\right), 16 \mathrm{~cm}^{-1}$ below the corresponding intense absorption in $\mathrm{SiO}_{2}\left(1380 \mathrm{~cm}^{-1}\right)$, and

TABLE I. Experimental and calculated harmonic vibrational frequencies (in $\mathrm{cm}^{-1}$ ) of $\mathrm{AlO}_{1-4}{ }^{-}$, including main contributions of local modes and irreducible representations (irrep) of the delocalized normal modes.

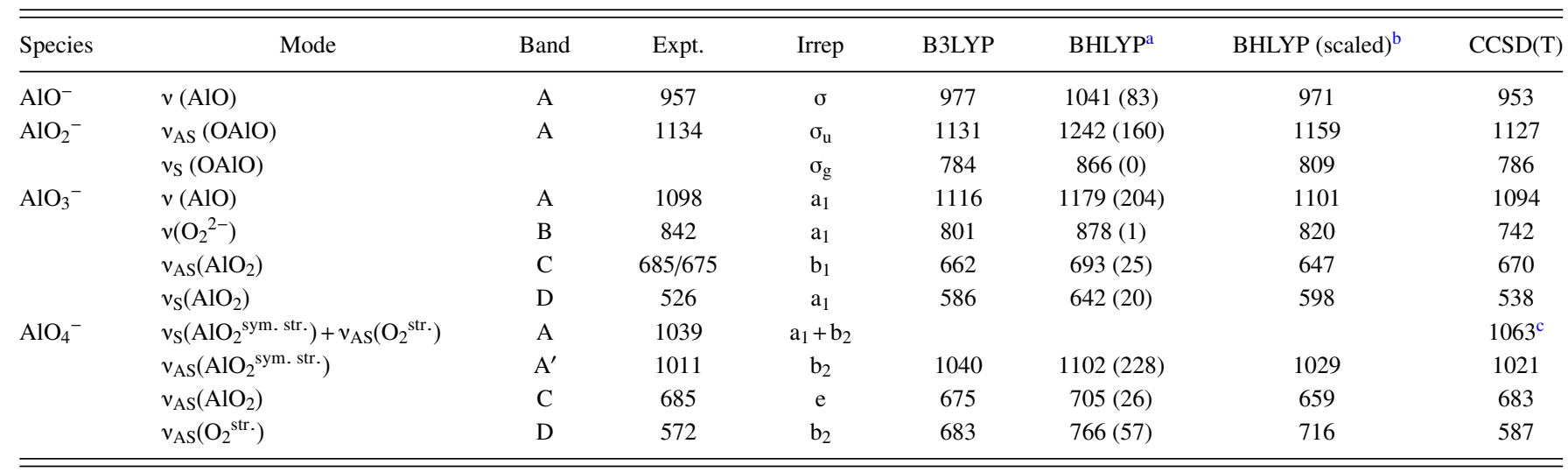

\footnotetext{
${ }^{\mathrm{a}} \mathrm{IR}$ intensities (in $\mathrm{km} / \mathrm{mol}$ ) are listed in parentheses.

${ }^{\mathrm{b}}$ Scaled with 0.9339 , taken from Table II of Ref. 73.

${ }^{\mathrm{c}}$ Sum of frequencies: $476 \mathrm{~cm}^{-1}\left(\mathrm{a}_{1}, v_{\mathrm{S}}\left(\mathrm{AlO}_{2}{ }^{\text {sym. str. }}\right)\right)$ and $587 \mathrm{~cm}^{-1}\left(\mathrm{~b}_{2}, \mathrm{v}_{\mathrm{AS}}\left(\mathrm{O}_{2}{ }^{\text {str. }}\right)\right)$.
} 
TABLE II. Experimental and calculated harmonic vibrational frequencies (in $\mathrm{cm}^{-1}$ ) of $\mathrm{Al}_{2} \mathrm{O}_{3-6}{ }^{-}$, including main contributions of local modes and irreducible representations (irrep) of the delocalized normal modes.

\begin{tabular}{|c|c|c|c|c|c|c|}
\hline Species & Mode & Band & Expt. & Irrep & BHLYP & $\operatorname{BHLYP}\left(\right.$ scaled) ${ }^{\mathrm{a}}$ \\
\hline \multirow[t]{5}{*}{$\mathrm{Al}_{2} \mathrm{O}_{3}^{-}$} & $v(\mathrm{AlO})$ & A & 1076 & $a_{1}$ & $1099^{\mathrm{b}}$ & 1026 \\
\hline & $2 v_{\mathrm{AS}, 2}$ (ring) & $\mathrm{A}^{\prime}$ & 1019 & & $1127^{\mathrm{b}}$ & 1053 \\
\hline & $v_{\mathrm{S}, 1}$ (ring), $v_{\mathrm{AS}, 1}$ (ring) & $\mathrm{C} / \mathrm{D}$ & $818 / 800$ & $a_{1} / b_{1}$ & $866 / 848$ & $809 / 791$ \\
\hline & $v_{\mathrm{S}, 2}($ ring $)$ & $\mathrm{G}$ & 629 & $\mathrm{a}_{1}$ & 667 & 623 \\
\hline & $v_{\mathrm{AS}, 2}($ ring $)$ & $\mathrm{H}$ & 539 & $\mathrm{~b}_{1}$ & 564 & 527 \\
\hline \multirow[t]{6}{*}{$\mathrm{Al}_{2} \mathrm{O}_{4}^{-}$} & $v(\mathrm{AlO})$ & A & 1024 & $\mathrm{a}_{1}$ & 1108 & 1035 \\
\hline & $v(\mathrm{AlO})$ & $\mathrm{C}$ & 913 & $a_{1}$ & 979 & 914 \\
\hline & $v_{\mathrm{AS}, 1}($ ring $)$ & $\mathrm{D}$ & 850 & $\mathrm{~b}_{1}$ & 903 & 843 \\
\hline & $v_{\mathrm{S}, 1}$ (ring) & $\mathrm{F}$ & 715 & $\mathrm{a}_{1}$ & 748 & 699 \\
\hline & $v_{\mathrm{S}, 2}($ ring $)$ & G & 606 & $a_{1}$ & 642 & 600 \\
\hline & $v_{\mathrm{AS}, 2}($ ring $)$ & $\mathrm{H}$ & 546 & $\mathrm{~b}_{1}$ & 574 & 535 \\
\hline \multirow[t]{6}{*}{$\mathrm{Al}_{2} \mathrm{O}_{5}^{-}$} & $v\left(\mathrm{O}_{2}^{-}\right)$ & $*$ & 1113 & $\mathrm{a}_{1}$ & 1288 & 1202 \\
\hline & $v(\mathrm{AlO})$ & A & 1022 & $\mathrm{a}_{1}$ & 1107 & 1032 \\
\hline & $v_{\mathrm{S}, 1}($ ring $)$ & $\mathrm{C}$ & $907 / 921$ & $\mathrm{a}_{1}$ & 947 & 884 \\
\hline & $v_{\mathrm{AS}, 1}$ (ring) & $\mathrm{D}$ & 851 & $\mathrm{~b}_{1}$ & 905 & 844 \\
\hline & $v_{\mathrm{S}, 2}$ (ring) & G & 650 & $a_{1}$ & 692 & 645 \\
\hline & $v_{\mathrm{AS}, 2}$ (ring) & $\mathrm{H}$ & 554 & $\mathrm{~b}_{1}$ & 581 & 542 \\
\hline \multirow[t]{9}{*}{$\mathrm{Al}_{2} \mathrm{O}_{6}^{-}$} & $v\left(\mathrm{O}_{2}^{-}\right)$ & $*$ & 1016 & $\mathrm{a}_{1}$ & 1287 & 1202 \\
\hline & $v\left(\mathrm{Al}-\mathrm{O}_{2}{ }^{2-}\right)$ & $\mathrm{B}$ & 937 & $a_{1}$ & 1008 & 941 \\
\hline & $v_{\mathrm{S}, 1}($ ring $)$ & $\mathrm{C}$ & 900 & $\mathrm{a}_{1}$ & 943 & 881 \\
\hline & $v_{\mathrm{AS}, 1}($ ring $)$ & $\mathrm{D}$ & 855 & $\mathrm{~b}_{1}$ & 903 & 842 \\
\hline & & $\mathrm{E}$ & $819 / 807$ & & & \\
\hline & $v\left(\mathrm{O}_{2}^{2-}\right)$ & $\mathrm{F}$ & 729 & $a_{1}$ & 777 & 726 \\
\hline & $v_{\mathrm{AS}, 2}(\mathrm{OAlO})$ & & & $\mathrm{b}_{2}$ & 701 & 655 \\
\hline & $v_{\mathrm{S}, 2}$ (ring) & G & 640 & $\mathrm{a}_{1}$ & 694 & 648 \\
\hline & $v_{\mathrm{AS}, 2}($ ring $)$ & $\mathrm{H}$ & 560 & $\mathrm{~b}_{1}$ & 597 & 558 \\
\hline
\end{tabular}

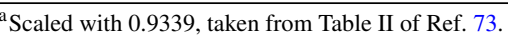

${ }^{\mathrm{b}}$ Anharmonic BHLYP frequencies: 1089 and $1046 \mathrm{~cm}^{-1}$ (Fermi resonance).

two weaker absorptions roughly $500 \mathrm{~cm}^{-1}$ lower in energy at 877 and $855 \mathrm{~cm}^{-1}$. This compares favorably with the present IRPD spectrum of $\mathrm{AlO}_{3}{ }^{-}$, which is characterized by a red shift of the most intense absorption (versus $\mathrm{AlO}_{2}^{-}$) of $36 \mathrm{~cm}^{-1}$ and considerably weaker features $\sim 420 \mathrm{~cm}^{-1}$ lower in energy, indicating a similar geometric arrangement as in $\mathrm{SiO}_{3}$. A $C_{2 v}$ structure with a peroxo-group as part of a threemembered ring has also been predicted for the ground state of $\mathrm{GaO}_{3}{ }^{-} .62$

Finally, the IRPD spectrum of $\mathrm{D}_{2}$-tagged $\mathrm{AlO}_{4}{ }^{-}$exhibits four bands at 1039 (A), $1011\left(\mathbf{A}^{\prime}\right), 685(\mathbf{C})$, and $572 \mathrm{~cm}^{-1}$ (D). It looks rather similar to that of $\mathrm{AlO}_{3}{ }^{-}$suggesting a related geometry. The main difference is two bands instead of one band above $1000 \mathrm{~cm}^{-1}$, which are also slightly red-shifted compared to the corresponding band in $\mathrm{AlO}_{3}{ }^{-}$. No experimental reference data for either neutral $\mathrm{SiO}_{4}$ or group III tetraoxide anions are available in the literature. A highly symmetric $\left(D_{2 \mathrm{~d}}\right){ }^{1} \mathrm{~A}_{1}$ ground state has been predicted for $\mathrm{AlO}_{4}^{-}$, which is characterized by three IRactive bands in-between $400-1200 \mathrm{~cm}^{-1}$ instead of four that are observed in the present IRPD spectrum. ${ }^{36}$ An assignment to a kite-like $\mathrm{O}-\mathrm{Al}-\mathrm{O}_{3}$ structure, as predicted for $\mathrm{GaO}_{4}{ }^{-}$, is unlikely, as the most intense IR transition associated with this structure is expected at a lower energy $\left(862 \mathrm{~cm}^{-1}\right)$, a region where no transition is observed in the IRPD spectrum of $\mathrm{AlO}_{4}{ }^{-63}$

\section{Dialuminum oxide anions}

The IRPD spectra of $\mathrm{Al}_{2} \mathrm{O}_{3-6}{ }^{-}$(see Fig. 1) show considerably more IR activity compared to those of the mono-aluminum oxide anions, in particular in-between 700 and $950 \mathrm{~cm}^{-1}$. The $\mathrm{Al}_{2} \mathrm{O}_{3-6}{ }^{-}$spectra share common features, including strong IR-activity near $850 \mathrm{~cm}^{-1}$ (band $\mathbf{C}$ and $\mathbf{D}$ ) as well as two characteristic bands, labeled $\mathbf{G}$ and $\mathbf{H}$, between 500 and $700 \mathrm{~cm}^{-1}$, indicating that they share a common geometric motif. Previous APE spectra for $\mathrm{Al}_{2} \mathrm{O}_{2-5}{ }^{-}$reported by Desai et al..$^{18}$ found that this common motif is a $\mathrm{Al}-(\mathrm{O})_{2}-\mathrm{Al}$ rhombic ring. Such cyclic structures have also been predicted for $\mathrm{B}_{2} \mathrm{O}_{4}{ }^{-}, \mathrm{Ga}_{2} \mathrm{O}_{3-4^{-}}$, and the $\mathrm{Si}_{2} \mathrm{O}_{3}{ }^{62,64-66}$ The lower energy absorptions can then likely be assigned to various vibrational modes involving this four-membered ring. ${ }^{67,68}$

The previous APE study also suggested that $\mathrm{Al}_{2} \mathrm{O}_{3-5}{ }^{-}$exhibits terminal $\mathrm{Al}-\mathrm{O}$ groups and, indeed, the IRPD spectra of $\mathrm{Al}_{2} \mathrm{O}_{3-5}{ }^{-}$are characterized by strong absorptions slightly above $1000 \mathrm{~cm}^{-1}$, typical for the presence of such terminal Al-O groups. However, the number of IRPD bands observed (e.g., two for $\mathrm{Al}_{2} \mathrm{O}_{3}{ }^{-}$) does not always correlate with the number of terminal $\mathrm{Al}-\mathrm{O}$ groups expected (e.g., one for $\mathrm{Al}_{2} \mathrm{O}_{3}{ }^{-}$), requiring further explanation (see below). No significant absorption is observed in this region for $\mathrm{Al}_{2} \mathrm{O}_{6}{ }^{-}$, supporting the predicted $\mathrm{O}_{2}-\mathrm{Al}-(\mathrm{O})_{2}-\mathrm{Al}-\mathrm{O}_{2}$ structure, which contains two terminal $\eta^{2}-\mathrm{O}_{2}$ groups but no terminal O-atoms. ${ }^{7}$ 
In more detail, the IRPD spectrum of $\mathrm{Al}_{2} \mathrm{O}_{3}{ }^{-} \cdot \mathrm{D}_{2}$ is characterized by five absorption features at 1076 (A), 1019 $\left(\mathbf{A}^{\prime}\right), \sim 818 / 800(\mathbf{C} / \mathbf{D}), 629(\mathbf{G})$, and $539 \mathrm{~cm}^{-1}(\mathbf{H})$. Four of these bands $(\mathbf{C}, \mathbf{D}, \mathbf{G}$, and $\mathbf{H})$ are also observed in the IRPD spectrum of $\mathrm{Al}_{2} \mathrm{O}_{4}^{-} \cdot \mathrm{D}_{2}$. While no absorption corresponding to band $\mathbf{A}$ in the $\mathrm{Al}_{2} \mathrm{O}_{3}{ }^{-} \cdot \mathrm{D}_{2}$ spectrum is observed; however an additional intense feature appears at $913 \mathrm{~cm}^{-1}(\mathbf{C})$. The IRPD spectrum of $\mathrm{Al}_{2} \mathrm{O}_{5}{ }^{-} \cdot \mathrm{D}_{2}$ looks very similar to that of $\mathrm{Al}_{2} \mathrm{O}_{4}{ }^{-} \cdot \mathrm{D}_{2}$ with five bands at $1022(\mathbf{A}), \sim 907(\mathbf{C}), 851$ (D), $650(\mathbf{G})$, and $554 \mathrm{~cm}^{-1}(\mathbf{H})$, but no absorption in the vicinity of the weak feature $\mathbf{F}\left(715 \mathrm{~cm}^{-1}\right)$ observed for $\mathrm{Al}_{2} \mathrm{O}_{4}{ }^{-} \cdot \mathrm{D}_{2}$. Note, for $\mathrm{Al}_{2} \mathrm{O}_{4}{ }^{-}$ and $\mathrm{Al}_{2} \mathrm{O}_{5}{ }^{-}$Desai et al. ${ }^{18}$ reported features at low electron binding energies in the APE spectra that they assigned to hot bands involving vibrational modes at $1090 \mathrm{~cm}^{-1}\left(\mathrm{Al}_{2} \mathrm{O}_{4}{ }^{-}\right)$and $1170 \mathrm{~cm}^{-1}\left(\mathrm{Al}_{2} \mathrm{O}_{5}{ }^{-}\right)$. We find no evidence of IR-active modes at such high energies, suggesting that these modes are either not IR-active or these features are of other origin. Finally, the IRPD spectrum of $\mathrm{Al}_{2} \mathrm{O}_{6}{ }^{-} \cdot \mathrm{D}_{2}$ resembles that of $\mathrm{Al}_{2} \mathrm{O}_{5}{ }^{-} \cdot \mathrm{D}_{2}$ with respect to the bands $\mathbf{C}, \mathbf{D}, \mathbf{G}$, and $\mathbf{H}$. It shows additional features at $937(\mathbf{B}), \sim 819(\mathbf{E})$, and $729 \mathrm{~cm}^{-1}(\mathbf{F})$, and lacks any significant absorption above $950 \mathrm{~cm}^{-1}$.

\section{B. Computational results}

\section{Monoaluminum oxide clusters $\mathrm{AlO}_{1-4}{ }^{-}$}

$\mathrm{AlO}^{-}$and $\mathrm{AlO}_{2}^{-}$are electronic closed-shell systems and all three computational methods (B3LYP, BHLYP, and $\operatorname{CCSD}(\mathrm{T})$ ) predict the same electronic and geometric structures. $\mathrm{CCSD}(\mathrm{T})$ and $\mathrm{B} 3 \mathrm{LYP}$ vibrational frequencies are close to the experimental ones, while the BHLYP frequencies are blue-shifted (see Table I). Previous CCSD(T) calculations on $\mathrm{AlO}^{-}$predicted a harmonic vibrational frequency of $969 \mathrm{~cm}^{-1}$ and an equilibrium bond length of $164 \mathrm{pm},{ }^{26}$ whereas our $\operatorname{CCSD}(\mathrm{T}) / \mathrm{aCVTZ}$ calculations yield values of $953 \mathrm{~cm}^{-1}$ and $165 \mathrm{pm}$, respectively. In $\mathrm{AlO}_{2}^{-}$, the $\mathrm{Al}-\mathrm{O}$ stretching mode is predicted higher $\left(1127 \mathrm{~cm}^{-1}\right)$ and the bond distance is slightly shorter (164 pm).

For $\mathrm{AlO}_{3}^{-}, \mathrm{B} 3 \mathrm{LYP}$ and $\mathrm{CCSD}(\mathrm{T})$ calculations yield a closed-shell singlet ground state with a planar $\mathrm{O}-\mathrm{Al}-\mathrm{O}_{2}$ structure of $C_{2 \mathrm{v}}$ symmetry (see Fig. 2) containing a peroxo group (155 pm). In contrast, an open-shell species with three isolated oxygen atoms as part of a distorted $D_{3 \mathrm{~h}}$ structure (see Fig. 2) is predicted at slightly lower energy using BHLYP. Using B3LYP and CCSD(T), this species has significantly higher energies, 39 and $87 \mathrm{~kJ} / \mathrm{mol}$, see Fig. 3 .

The harmonic IR spectra (BHLYP) of both of these structures are compared to the experimental IRPD spectrum in Fig. 2. The agreement is much better for the $\mathrm{O}-\mathrm{Al}-\mathrm{O}_{2}$ structure (singlet state) than for the $\mathrm{Al}(-\mathrm{O})_{3}$ structure (triplet state). For the $\mathrm{O}-\mathrm{Al}-\mathrm{O}_{2}$ structure, the calculations yield three IR-active bands at 1179, 693, and $642 \mathrm{~cm}^{-1}$. While the BHLYP frequencies are significantly blue-shifted by up to $120 \mathrm{~cm}^{-1}$ with respect to the experimentally observed IRPD bands $\mathbf{A}, \mathbf{C}$, and $\mathbf{D}$ (see Table I), the relative band positions and intensities agree favorably, supporting an assignment to the closed-shell $C_{2 \mathrm{v}}$ structure. As in $\mathrm{AlO}^{-}$and $\mathrm{AlO}_{2}{ }^{-}$, the terminal Al-O stretching mode of $\mathrm{AlO}_{3}{ }^{-}$is calculated highest in energy $\left(1179 \mathrm{~cm}^{-1}\right)$. The two bands at lower energies then correspond to the antisymmetric and symmetric stretching

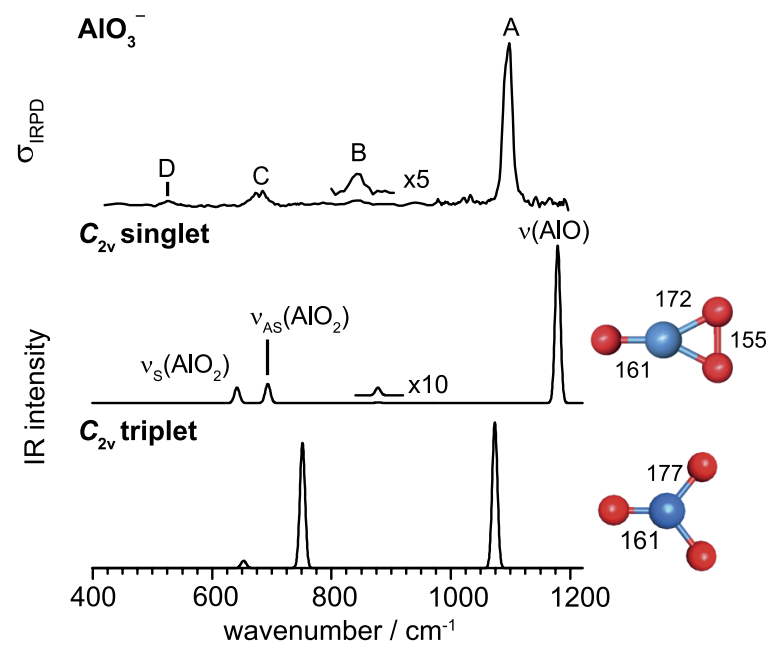

FIG. 2. IRPD spectrum of $\mathrm{D}_{2}$-tagged $\mathrm{AlO}_{3}{ }^{-}$(top) compared to simulated IR spectra derived from harmonic BHLYP vibrational frequencies and intensities of low energy structures $(\mathrm{Al}=$ blue, $\mathrm{O}=$ red, bond lengths are in $\mathrm{pm}$ ). Assignments of the IR-active vibrational modes are indicated ( $v$ : stretch, $v_{\mathrm{S}} / v_{\mathrm{AS}}$ : symmetric/antisymmetric stretch). See Table I for band positions and assignments.

mode of the Al- $\mathrm{O}_{2}$ moiety (see Fig. 4). The intensity of the peroxide stretching mode at $878 \mathrm{~cm}^{-1}$ is found to be small $(<1 \%$ relative intensity) by BHLYP. Indeed, we observe a small feature, labeled B in Fig. 2, at $842 \mathrm{~cm}^{-1}$ that could tentatively be attributed to this mode. Note, the $\operatorname{CCSD}(\mathrm{T})$ calculations (see Table I) predict the peroxide stretching mode at considerably lower energy $\left(742 \mathrm{~cm}^{-1}\right)$.

For $\mathrm{AlO}_{4}^{-}$, the genetic algorithm yields three low energy structures shown in Fig. 5. Fig. 3 (right panel) shows the relative stability of these structures as obtained with different methods. These are a $D_{2 \mathrm{~d}}$ structure containing two $\eta^{2}$-peroxo motifs, a planar $C_{2 \mathrm{v}}$ structure containing an $\mathrm{O}_{3}$ moiety $(+14$ $\mathrm{kJ} / \mathrm{mol}$ ), and a non-planar biradical $C_{\mathrm{s}}$ structure containing a single $\eta^{2}$-superoxo motif $(+18 \mathrm{~kJ} / \mathrm{mol})$. The $C_{\mathrm{s}}$ structure may be considered as a superoxide radical $\mathrm{O}_{2}{ }^{-\cdot}$. coordinated to an asymmetric, bent $\mathrm{AlO}_{2}$ radical with the extra electron localized on a single oxygen atom. In previous work, ${ }^{36}$ the ground state structure was assumed to be a singlet state of $D_{2 \mathrm{~d}}$ symmetry, consistent with the B3LYP, BHLYP, and CCSD(T) results of this work.

There are two possible assignments for the experimental spectrum shown in Fig. 5: (i) The harmonic BHLYP results for the $C_{\mathrm{s}}$ structure may explain three of the four bands of the experimental IR spectrum. The calculated IR-active bands at 1081,722 , and $524 \mathrm{~cm}^{-1}$ which correspond to
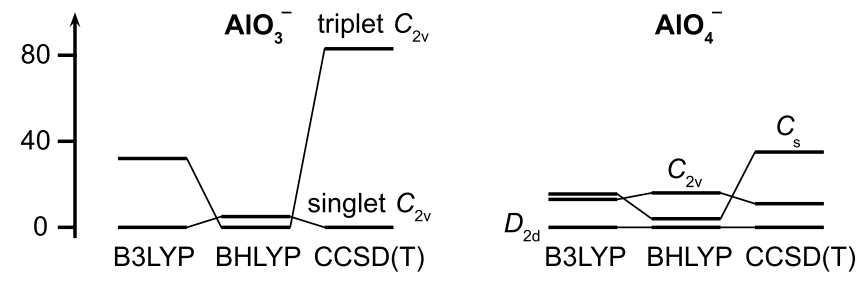

FIG. 3. Relative energies (in $\mathrm{kJ} / \mathrm{mol}$ ) of the low-energy isomers of $\mathrm{AlO}_{3}{ }^{-}$and $\mathrm{AlO}_{4}{ }^{-}$computed with different methods. 


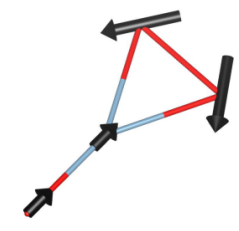

$v_{\mathrm{S}}\left(\mathrm{AlO}_{2}\right)$

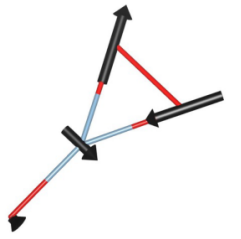

$v_{\mathrm{AS}}\left(\mathrm{AlO}_{2}\right)$

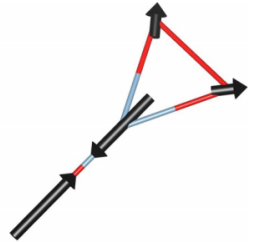

$v(\mathrm{AlO})$
FIG. 4. Visualization of three normal modes ( $v$ : stretch, $v_{\mathrm{S}} / v_{\mathrm{AS}}$ : symmetric/ antisymmetric stretch) of the closed-shell $C_{2 \mathrm{v}}$ structure of $\mathrm{AlO}_{3}{ }^{-}$.

excitations of the Al-O stretch $v_{1}$ involving the shorter Al-O bond $(161 \mathrm{pm})$, the Al-O stretch $v_{2}$ of the longer $\mathrm{Al}-\mathrm{O}$ bond $(176 \mathrm{pm})$, and the symmetric stretch $v_{\mathrm{S}}$ of the $\mathrm{AlO}_{2} \eta^{2}$-superoxo motif, respectively, can be assigned to bands $\mathbf{A}, \mathbf{C}$, and $\mathbf{D}$, respectively. The fourth observed band $\mathbf{A}^{\prime}$ may result from a Fermi resonance as anharmonic BHLYP calculations of the biradical $C_{\mathrm{s}}$ structure show (see Fig. 5). A resonance between the first overtone $2 v_{\mathrm{S}}$ and the $v_{1}$ fundamental yields a doublet at 996 and $1068 \mathrm{~cm}^{-1}$ (see Fig. 5), which could be attributed to bands $\mathrm{A}^{\prime}$ and $\mathrm{A}$, respectively. However, quantitative agreement for the band positions is not achieved.
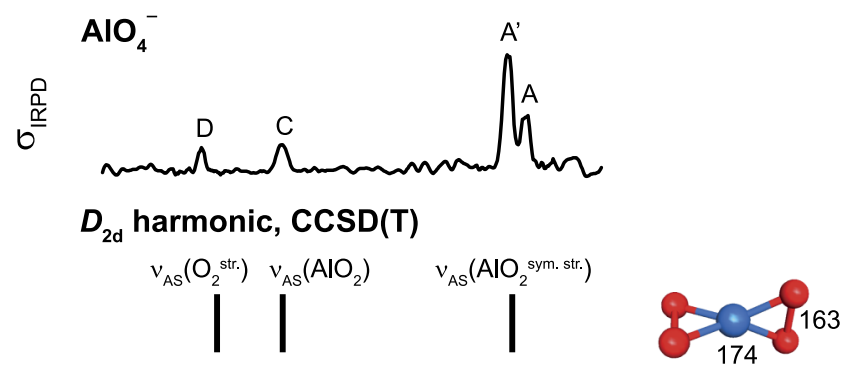

$D_{2 \mathrm{~d}}$ harmonic

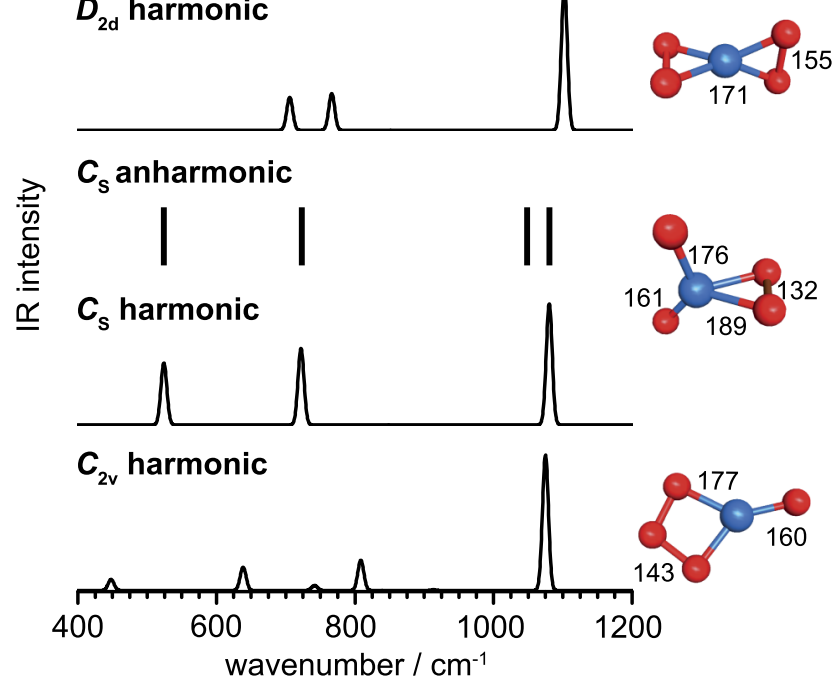

FIG. 5. IRPD spectrum of $\mathrm{D}_{2}$-tagged $\mathrm{AlO}_{4}{ }^{-}$(top) compared to calculated IR spectra of low-energy structures (bond length are in pm) of $\mathrm{AlO}_{4}{ }^{-}$. The harmonic $\operatorname{CCSD}(\mathrm{T})$ stick spectrum (no intensities available) is shown beneath the experimental spectrum. All other panels show BHLYP results for different structures. Since intensities are not available the anharmonic BHLYP results for the $C_{\mathrm{s}}$ structure are also shown as stick spectrum. Assignments of the IR-active vibrational modes are indicated $\left(v_{\mathrm{S}} / v_{\mathrm{AS}}\right.$ : symmetric/antisymmetric stretch) and summarized together with experimental and calculated band positions in Table I. See text for details. (ii) The harmonic $\operatorname{CCSD}(\mathrm{T})$ results of the $D_{2 \mathrm{~d}}$ structure for the band position are in very good agreement with the experiment. The most intense band $\mathbf{A}^{\prime}$ at $1011 \mathrm{~cm}^{-1}$ is calculated at $1021 \mathrm{~cm}^{-1}$ and corresponds to $v_{\mathrm{AS}}\left(\mathrm{AlO}_{2}{ }^{\text {sym. str. }}\right)$, an antisymmetric combination $\left(\mathrm{b}_{2}\right)$ of the two $\mathrm{AlO}_{2}$ symmetric stretches. The $\mathrm{C}$ and $\mathrm{D}$ bands at 685 and $572 \mathrm{~cm}^{-1}$ then are $v_{\mathrm{AS}}\left(\mathrm{AlO}_{2}\right)$, the two degenerate $\mathrm{AlO}_{2}$ antisymmetric stretches (e), and $\mathrm{v}_{\mathrm{AS}}\left(\mathrm{O}_{2}{ }^{\text {str. }}\right)$, the antisymmetric combination $\left(\mathrm{b}_{2}\right)$ of the two $\mathrm{O}_{2}$ stretches, respectively, calculated at $683 \mathrm{~cm}^{-1}$ (e) and $587 \mathrm{~cm}^{-1}\left(\mathrm{~b}_{2}\right)$. Band $\mathbf{A}$ cannot be explained by a calculated fundamental transition. However, similar to the above discussed anharmonic spectrum of the $C_{\mathrm{s}}$ structure, the $v_{\mathrm{S}}\left(\mathrm{AlO}_{2}{ }^{\text {sym. str. }}\right)+v_{\mathrm{AS}}\left(\mathrm{O}_{2}^{\text {str. }}\right)$ combination band (see Table $\left.\mathrm{I}\right)$ is expected close in energy to the $v_{\mathrm{AS}}\left(\mathrm{AlO}_{2}{ }^{\text {sym. str. }}\right)$ fundamental and could borrow intensity from it by way of Fermi coupling. B3LYP and BHLYP also show all these bands; however, the energetic ordering of the modes at 685 and $572 \mathrm{~cm}^{-1}$ (Bands $\mathbf{C}$ and $\mathbf{D}$ ) is exchanged. The too high $\mathrm{v}_{\mathrm{AS}}\left(\mathrm{O}_{2}{ }^{\text {str. }}\right)$ frequency is also reflected in a too short bond distance in BHLYP of $155 \mathrm{pm}$, compared to $163 \mathrm{pm}$ in $\operatorname{CCSD}(\mathrm{T}$ ) (see Fig. 5). We therefore assign the IRPD spectrum of $\mathrm{AlO}_{4}{ }^{-}$to an electronically closed-shell $D_{2 \mathrm{~d}}$ structure, because (i) of the better agreement of the simulated spectrum with experiment and (ii) of its much lower CCSD(T) energy.

\section{Dialuminum oxide clusters $\mathrm{Al}_{2} \mathrm{O}_{3-6}{ }^{-}$}

The BHLYP global minimum-energy structure of $\mathrm{Al}_{2} \mathrm{O}_{3}{ }^{-}$ is a planar $\mathrm{Al}-\left(\mathrm{O}_{2}\right)-\mathrm{Al}$ ring with an exocyclic oxygen atom radical and overall $C_{2 \mathrm{v}}$ symmetry, see Fig. 6. A noncyclic $C_{2 \mathrm{v}}$ isomer is found more than $100 \mathrm{~kJ} / \mathrm{mol}$ higher in energy.

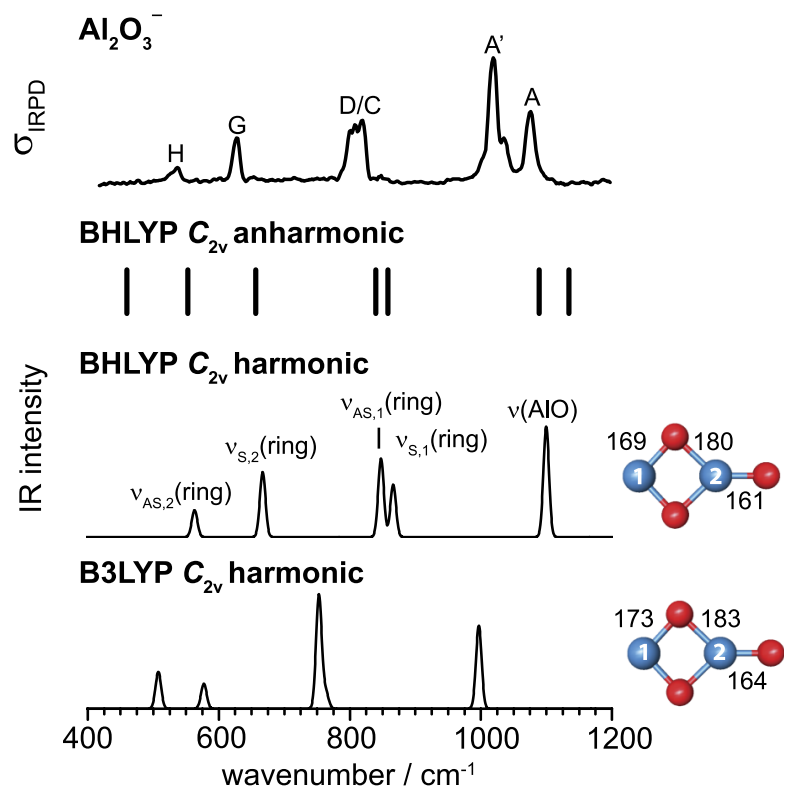

FIG. 6. IRPD spectrum of $\mathrm{D}_{2}$-tagged $\mathrm{Al}_{2} \mathrm{O}_{3}{ }^{-}$(top) compared to simulated BHLYP anharmonic frequencies and harmonic IR spectrum of the minimumenergy structure (bond lengths in pm) of $\mathrm{Al}_{2} \mathrm{O}_{3}{ }^{-}$. The $\mathrm{B} 3 \mathrm{LYP}$ harmonic spectrum is also shown with the minimum structure. Assignments of the IR-active vibrational modes are indicated $\left(v\right.$ : stretch, $v_{\mathrm{S}} / v_{\mathrm{AS}}$ : symmetric/antisymmetric $\mathrm{Al}-(\mathrm{O})_{2}$ stretch, "1", and " 2 " refer to the doubly and triply coordinated Al-atom, respectively). See Table II for band positions and assignments. 
Five of the six features observed in the IRPD spectrum of $\mathrm{Al}_{2} \mathrm{O}_{3}{ }^{-}$are reproduced by the harmonic BHLYP calculation (see Fig. 6). However, the most intense band $\mathbf{A}^{\prime}$ at $1019 \mathrm{~cm}^{-1}$ is missing in the simulated spectrum. Band $\mathbf{A}$ corresponds to the stretching mode of the terminal Al-O group (harmonic $1099 \mathrm{~cm}^{-1}$ ). Bands $\mathbf{C}, \mathbf{D}, \mathbf{G}$, and $\mathbf{H}$ correspond to four characteristic modes involving the $\mathrm{Al}-(\mathrm{O})_{2}-\mathrm{Al}$ ring, respectively. These four ring modes are observed for all dialuminum oxide anions studied here. They are best visualized as symmetric and antisymmetric stretches of the $\mathrm{Al}-(\mathrm{O})_{2}$ moieties involving one or the other Al-atom, labeled as $v_{\mathrm{S}, 1}$ (harmonic $866 \mathrm{~cm}^{-1}, \mathbf{C}$ ), $v_{\mathrm{AS}, 1}$ (harmonic $847 \mathrm{~cm}^{-1}, \mathbf{D}$ ), $v_{\mathrm{S}, 2}$ (harmonic $668 \mathrm{~cm}^{-1}, \mathbf{G}$ ), and $v_{\mathrm{AS}, 2}$ (harmonic $564 \mathrm{~cm}^{-1}, \mathbf{H}$ ) in Fig. 6, where the index 1 (2) refers to the doubly (triply) coordinated $\mathrm{Al}$-atom in $\mathrm{Al}_{2} \mathrm{O}_{3}{ }^{-}$. This leaves band $\mathbf{A}^{\prime}$ unassigned, whose identity is revealed by the BHLYP anharmonic calculation (see Fig. 6). It results from Fermitype coupling involving the overtone $2 v_{\mathrm{AS}, 2}$, which borrows intensity from the intense $v(\mathrm{Al}-\mathrm{O})$ stretch fundamental, resulting in anharmonic frequencies calculated at $1046 \mathrm{~cm}^{-1}$ (A') and $1089 \mathrm{~cm}^{-1}$ (A).

The predicted structures of $\mathrm{Al}_{2} \mathrm{O}_{4}{ }^{-}$are strongly affected by the different balance of electron delocalization versus localization across the DFT functionals. Both BHLYP and B3LYP functionals predict an $\mathrm{Al}-(\mathrm{O})_{2}-\mathrm{Al}$ ring with two terminal oxygen atoms and similar structural parameters, see Fig. 7. However, B3LYP yields a higher symmetric $D_{2 \mathrm{~h}}$ structure, which corresponds to an energetically high-lying local minimum in BHLYP, while BHLYP localizes the electron on one of the two terminal oxygen atoms, resulting in a more distorted $C_{2 \mathrm{v}}$ structure. Consequently, the predicted harmonic spectra of these two structures are characteristically different, with the higher symmetry $D_{2 \mathrm{~h}}$ species yielding a much simpler IR spectrum with three instead of seven IR-active bands. For example, the symmetric stretching mode involving the two terminal Al-O bonds is IR-forbidden for the $D_{2 \mathrm{~h}}$ structure, but IR active for $C_{2 \mathrm{v}}$ structure $\left(1108 \mathrm{~cm}^{-1}\right)$. Indeed, the symmetry lowering induced by the electron localization with BHLYP results in an IR spectrum that qualitatively

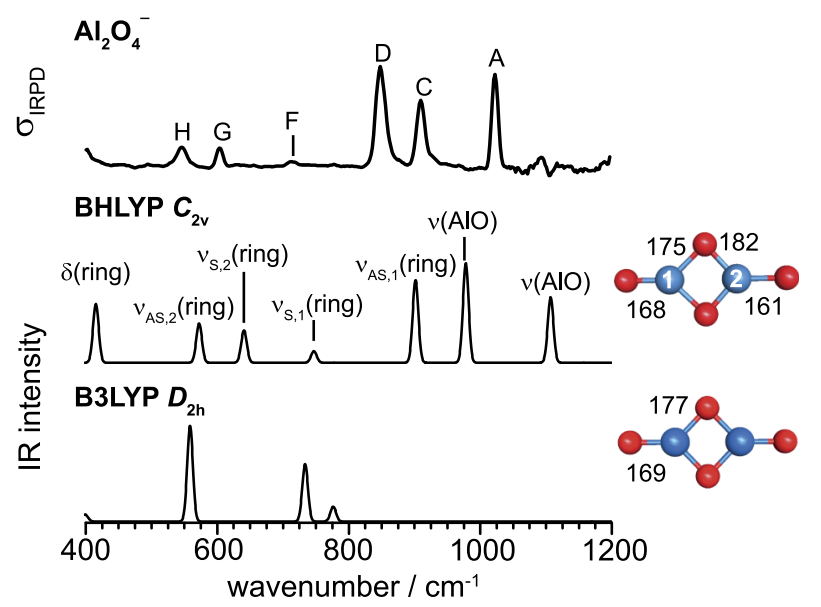

FIG. 7. IRPD spectrum of $\mathrm{D}_{2}$-tagged $\mathrm{Al}_{2} \mathrm{O}_{4}{ }^{-}$(top) compared to simulated BHLYP harmonic IR spectrum of the $C_{2 \mathrm{v}}$ minimum-energy structure (bond lengths in pm) of $\mathrm{Al}_{2} \mathrm{O}_{4}{ }^{-}$. The B3LYP harmonic spectrum of the $D_{2 \mathrm{~h}}$ structure is also shown (see text). See Table II for band positions and assignments. agrees with the experimental one (see Fig. 7) and allows assigning all six observed bands. Whereas bands $\mathbf{A}$ and $\mathbf{C}$ correspond to the terminal $\mathrm{Al}=\mathrm{O}$ and $\mathrm{Al}-\mathrm{O}$ stretching modes, respectively, bands $\mathbf{D}, \mathbf{F}, \mathbf{G}$, and $\mathbf{H}$ correspond to the four characteristic ring deformation modes $v_{\mathrm{S}, 1}, v_{\mathrm{AS}, 1}, v_{\mathrm{S}, 2}$, and $v_{\mathrm{AS}, 2}$, respectively. Note, the different energetic ordering of the four ring modes for $\mathrm{Al}_{2} \mathrm{O}_{4}{ }^{-}$compared to $\mathrm{Al}_{2} \mathrm{O}_{3}{ }^{-}$which results from a pronounced coupling between the $v(\mathrm{Al}-\mathrm{O})$ and $v_{\mathrm{S}, 1}$ mode, and red shifts the $v_{\mathrm{S}, 1}$ mode below $800 \mathrm{~cm}^{-1}$ in $\mathrm{Al}_{2} \mathrm{O}_{4}{ }^{-}$. Furthermore, the rise in intensity observed at the edge of the experimental IRPD spectrum around $400 \mathrm{~cm}^{-1}$ is attributed to the band onset of a ring out-of-plane bending mode.

$\mathrm{Al}_{2} \mathrm{O}_{5}{ }^{-}$also contains an $\mathrm{Al}-(\mathrm{O})_{2}-\mathrm{Al}$ ring with a terminal oxygen atom bound to one $\mathrm{Al}$ atom, and a superoxo group on the other $\mathrm{Al}$ atom. This removes the coupling between the $v(\mathrm{Al}-\mathrm{O})$ and $v_{\mathrm{S}, 1}($ ring) mode, observed for $n=4$, and restores the original energetic order of the four ring modes as in $\mathrm{Al}_{2} \mathrm{O}_{3}{ }^{-}$(and $\mathrm{Al}_{2} \mathrm{O}_{6}{ }^{-}$). Similar to $\mathrm{Al}_{2} \mathrm{O}_{4}{ }^{-}$, the charge delocalization of B3LYP yields a simulated spectrum that disagrees with the experimental one. Two very similar stable structures were found with BHLYP, namely, a peroxide and the superoxide structure. Their energies differ by less than $3 \mathrm{~kJ} / \mathrm{mol}$. The computed spectrum of the superoxide structure is in better agreement with the experimental one (see Fig. 8), indicating that this is the structure probed in the experiment. In particular, the distance between bands $\mathbf{A}$ and $\mathbf{C}$, and the appearance of only the two bands $\mathbf{G}$ and $\mathbf{H}$ in the $850-500 \mathrm{~cm}^{-1}$ region, is well-reproduced by the calculation for the superoxide structure. The superoxide symmetric stretching mode is predicted at $1288 \mathrm{~cm}^{-1}$ with very low intensity $(<1 \%$ relative intensity). We tentatively attribute it to the weak signal observed around $1113 \mathrm{~cm}^{-1}$ in the experimental spectrum, labeled “*” in Fig. 8.

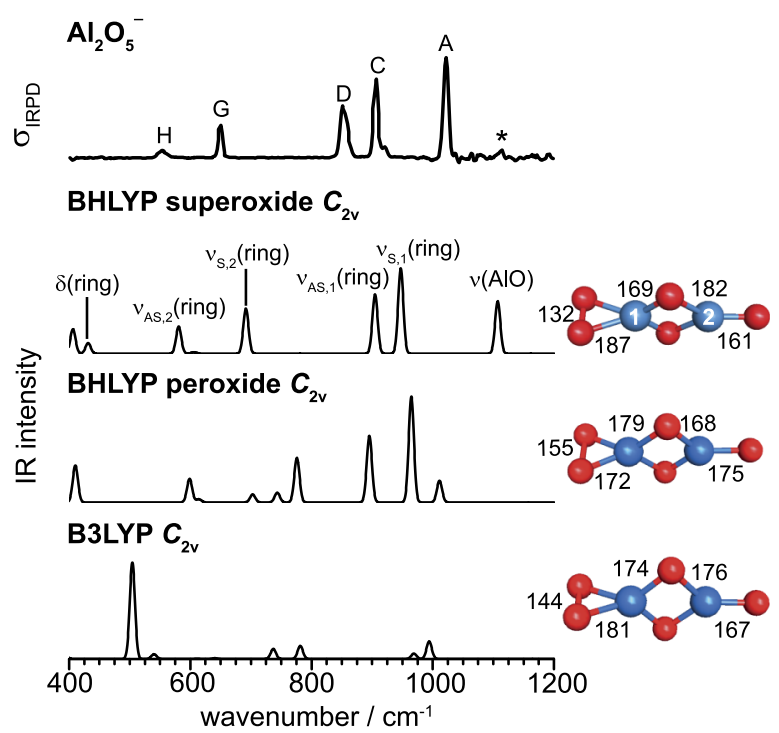

FIG. 8. IRPD spectrum of $\mathrm{D}_{2}$-tagged $\mathrm{Al}_{2} \mathrm{O}_{5}{ }^{-}$(top) compared to simulated BHLYP harmonic IR spectrum of the superoxide $C_{2 v}$ minimum-energy structure (bond lengths in pm) of $\mathrm{Al}_{2} \mathrm{O}_{5}{ }^{-}$. The BHLYP harmonic spectrum of the peroxide $C_{2 \mathrm{v}}$ structure and the B3LYP harmonic spectrum of the $C_{2 \mathrm{v}}$ structure are also shown (see text). See Table II for band positions and assignments. "*” denotes the weak absorption for O-O stretching. 


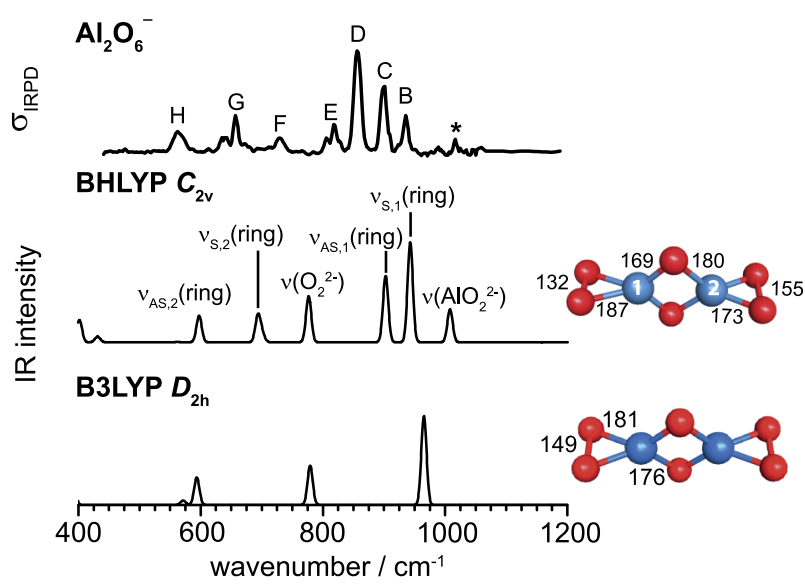

FIG. 9. Experimental IRPD spectrum of $\mathrm{D}_{2}$-tagged $\mathrm{Al}_{2} \mathrm{O}_{6}{ }^{-}$(top) compared to simulated BHLYP harmonic IR spectrum of the $C_{2 \mathrm{v}}$ minimum-energy structure (bond lengths in pm) of $\mathrm{Al}_{2} \mathrm{O}_{6}{ }^{-}$. The B3LYP harmonic spectrum of the $D_{2 \mathrm{~h}}$ structure is also shown (see text). See Table II for band positions and assignments. "*” denotes the weak absorption for $\mathrm{O}-\mathrm{O}$ stretching.

The $C_{2 \mathrm{v}}$ structure shown in Fig. 9 represents the global minimum-energy structure of $\mathrm{Al}_{2} \mathrm{O}_{6}{ }^{-}$on the BHLYP PES. This structure is derived from that of $\mathrm{Al}_{2} \mathrm{O}_{5}{ }^{-}$by replacing the single oxygen atom with a peroxo group. Hence, this structure contains a stretched peroxo (155 pm) and a superoxo (132 pm) group. As for $\mathrm{Al}_{2} \mathrm{O}_{4}{ }^{-}$, B3LYP yields a charge-delocalized $D_{2 \mathrm{~h}}$ structure, which represents an energetically higher lying minimum on the BHLYP PES.

Comparison of the simulated harmonic spectra with the experimental IRPD spectrum (see Fig. 9) supports an assignment to the $C_{2 \mathrm{v}}$ structure. Bands $\mathbf{B}$ and $\mathbf{F}$ correspond to the $\mathrm{Al}-\mathrm{O}_{2}$ and $\mathrm{O}-\mathrm{O}$ stretching modes involving the peroxo group. Bands $\mathbf{C}, \mathbf{D}, \mathbf{G}$, and $\mathbf{H}$ are the four in-plane ring deformation modes $v_{\mathrm{S}, 1}, v_{\mathrm{AS}, 1}, v_{\mathrm{S}, 2}$, and $v_{\mathrm{AS}, 2}$, respectively. The superoxo stretching mode is calculated at $1287 \mathrm{~cm}^{-1}$ with little IR activity $\left(<1 \%\right.$ relative intensity). Similar to $\mathrm{Al}_{2} \mathrm{O}_{5}{ }^{-}$, weaker features are indeed observed to the blue of the more intense IR transitions in the experimental spectrum. Band $\mathbf{E}$ has no counterpart in the simulated IR spectrum. ${ }^{16}$

\section{Discussion}

The common features observed in the IR spectra of small aluminum oxide clusters can be grouped in four spectral regions. Superoxo stretching modes are found at highest energies (1120-1010 $\left.\mathrm{cm}^{-1}\right)$, but with very little IR intensity, complicating their identification. Peroxo modes are considerably lower in energy $\left(850-570 \mathrm{~cm}^{-1}\right)$ and are predicted with slightly more IR intensity. Terminal Al-O stretching modes are found in the intermediate energy region (1140$960 \mathrm{~cm}^{-1}$ ). The vibrational frequencies of superoxo, peroxo, and terminal $\mathrm{Al}-\mathrm{O}$ groups are summarized in Table III.

The common structural motif of dialuminum oxide clusters is a four-membered $\mathrm{Al}-(\mathrm{O})_{2}-\mathrm{Al}$ ring to which additional O-atoms add in an exocyclic manner, similar to other metal oxide clusters, e.g., vanadium oxides.$^{68}$ This ring is characterized by four IR active in-plane ring deformation modes between 910 and $530 \mathrm{~cm}^{-1}$. The predicted energetic ordering is typically $v_{\mathrm{S}, 1}$ (ring) $>v_{\mathrm{AS}, 1}$ (ring) $>v_{\mathrm{S}, 2}($ ring $)>$ $v_{\mathrm{AS}, 2}$ (ring) with wavenumber ranges of $910-710 \mathrm{~cm}^{-1}\left(v_{\mathrm{S}, 1}\right)$, $860-800 \mathrm{~cm}^{-1}\left(v_{\mathrm{AS}, 1}\right), 650-600\left(v_{\mathrm{S}, 2}\right)$, and $560-530 \mathrm{~cm}^{-1}$ $\left(v_{\mathrm{AS}, 2}\right)$. Out of plane bending modes are predicted below $400 \mathrm{~cm}^{-1}$.

The electronic and geometric structures of the aluminum oxide clusters $\mathrm{Al}_{2} \mathrm{O}_{3-6}{ }^{-}$are governed by localization of the excess charge. In many cases, there is a competition between more symmetric structures with delocalized charge and less symmetric structures with more localized charge. As a consequence of charge localization, the electronic structures of the open-shell clusters $\mathrm{Al}_{2} \mathrm{O}_{n}{ }^{-}$are characterized by mixed valence ${ }^{51}$ Hence, the calculated electronic structure is very sensitive towards the amount of exact exchange that is mixed into the density functional. This is well known in the literature ${ }^{51,69}$ and has been observed before, e.g., with the size-induced d-electron localization in polyhedral vanadium oxide anion cages ${ }^{70}$ and the formation of electron holes in solid oxides. $^{71,72}$ The crossover point between DFT functionals with increasing amount of exact exchange for the physically correct description of the electronic structure depends on the observed system. In the present study, standard GGA functionals,

TABLE III. Experimental and calculated harmonic vibrational frequencies $\left(\mathrm{in}^{-1}\right.$ ) of different oxygen species in $\mathrm{AlO}_{1-4}{ }^{-}$and $\mathrm{Al}_{2} \mathrm{O}_{3-6}{ }^{-}$, including irreducible representations (irrep) of the delocalized normal modes.

\begin{tabular}{llcccc}
\hline \hline Species & Cluster & Expt. & Irrep & BHLYP (scaled) & Bond Length \\
\hline \multirow{2}{*}{ Superoxo } & $\mathrm{Al}_{2} \mathrm{O}_{5}{ }^{-}$ & 1113 & $\mathrm{a}_{1}$ & 1202 & 132 \\
& $\mathrm{Al}_{2} \mathrm{O}^{-}$ & 1016 & $\mathrm{a}_{1}$ & 1202 & 132 \\
\hline \multirow{4}{*}{ Terminal $\mathrm{Al}-\mathrm{O}$} & $\mathrm{AlO}_{2}{ }^{-}$ & 1134 & $\sigma_{\mathrm{u}}$ & 1159 & 163 \\
& $\mathrm{AlO}_{3}{ }^{-}$ & 1098 & $\mathrm{a}_{1}$ & 1101 & 161 \\
& $\mathrm{Al}_{2} \mathrm{O}_{3}{ }^{-}$ & 1076 & $\mathrm{a}_{1}$ & 1026 & 161 \\
& $\mathrm{Al}_{2} \mathrm{O}_{4}^{-}$ & 1024 & $\mathrm{a}_{1}$ & 1035 & 161 \\
& $\mathrm{Al}_{2} \mathrm{O}_{5}^{-}$ & 1022 & $\mathrm{a}_{1}$ & 1032 & 161 \\
& $\mathrm{AlO}^{-}$ & 962 & $\sigma$ & 971 & 164 \\
\hline \multirow{3}{*}{ Peroxo } & $\mathrm{Al}_{2} \mathrm{O}_{6}{ }^{-}$ & 729 & $\mathrm{a}_{1}$ & 726 & 155 \\
& $\mathrm{AlO}_{3}{ }^{-}$ & 842 & $\mathrm{a}_{1}$ & 820 & 155 \\
& $\mathrm{AlO}_{4}^{-}$ & 572 & $\mathrm{~b}_{2}$ & $716^{\mathrm{b}}$ & $155^{\mathrm{b}}$ \\
\hline \hline
\end{tabular}

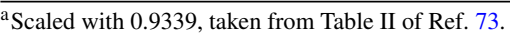

${ }^{\mathrm{b}} \mathrm{CCSD}(\mathrm{T})$ values: $587 \mathrm{~cm}^{-1}$ and $163 \mathrm{pm}$. 
and also hybrid functional with the standard amount of Fock exchange, e.g., $20 \%$ for B3LYP, incorrectly predict the electronic structure to be delocalized and the geometric structure to be $D_{2 \mathrm{~h}}$ symmetric (if possible by stoichiometric composition). However, BHLYP (50\% exchange) localizes the charge leading to a $C_{2 \mathrm{v}}$ symmetric distortion. The surplus electron is localized on a terminal $\mathrm{O}$-atom or $\mathrm{O}_{2}^{-}$group, as indicated by bond lengths and population analyses and confirmed by the agreement of simulated and experimental spectra.

With the exception of $\mathrm{AlO}_{3}{ }^{-}$, the BHLYP functional (50\% Fock exchange) provides a qualitatively correct description of all systems studied, although the calculated harmonic wavenumbers show a rather large rms deviation of $85 \mathrm{~cm}^{-1}$ for the 33 assigned wavenumbers in Tables I and II. Applying the global scale factor of $0.9339^{73}$ the rms deviation is reduced to $45 \mathrm{~cm}^{-1}$. If we use our data to derive a global scale factor, we obtain 0.919 with the rms value of $42 \mathrm{~cm}^{-1}$.

\section{SUMMARY}

We have studied the structure and vibrational spectra of small aluminum oxide cluster anions. The structures were determined computationally by using a genetic algorithm for finding the global minimum and subsequently confirmed by comparison of the predicted spectra with measured IRPD spectra. The mononuclear species $\mathrm{AlO}_{1,2}{ }^{-}$are linear, closedshell molecules. $\mathrm{AlO}_{3}{ }^{-}$has a planar, triangular structure with a peroxo group, and $\mathrm{AlO}_{4}{ }^{-}$is a closed-shell $D_{2 \mathrm{~d}}$ symmetric molecule with two overstretched peroxo groups. The binuclear species $\mathrm{Al}_{2} \mathrm{O}_{3-6}{ }^{-}$are all open-shell doublets and oxygencentered radicals. The common motif is a four-membered Al- $\left(\mathrm{O}_{2}\right)-\mathrm{Al}$ ring, with one or two terminal oxo groups $(n=3,4)$, or with oxo/superoxo $(n=5)$ and peroxo/superoxo groups $(n=6)$. The electronic structure is characterized by the localization of the unpaired electron on one side of the cluster, lowering its symmetry from $D_{2 \mathrm{~h}}$ to $C_{2 \mathrm{v}}$ (for $n=4,6$ ). A correct description requires the use of density functionals with a large amount of Fock exchange such as BHLYP, otherwise the electron will delocalize and the vibrational spectra will not be reproduced.

\section{ACKNOWLEDGMENTS}

This research is supported by the Collaborative Research Center 1109 of the German Research Foundation DFG. We thank Professor Ludger Wöste for providing the magnetron sputter ion source. Xiaowei Song thanks the Alexander-vonHumboldt Foundation for a post-doctoral research fellowship. The authors also thank the reviewer for pointing out technical issues with the $\operatorname{CCSD}(\mathrm{T})$ calculations.

\footnotetext{
${ }^{1}$ M. Trueba and S. P. Trasatti, Eur. J. Inorg. Chem. 17, 3393-3403 (2005).

${ }^{2}$ K. R. Asmis, Phys. Chem. Chem. Phys. 14, 9270-9281 (2012).

${ }^{3}$ J. Sauer and H.-J. Freund, Catal. Lett. 145, 109-125 (2015).

${ }^{4}$ D. K. Böhme and H. Schwarz, Angew. Chem., Int. Ed. 44, 2336-2354 (2005).

${ }^{5}$ S. Feyel, J. Döbler, R. Hökendorf, M. K. Beyer, J. Sauer, and H. Schwarz, Angew. Chem., Int. Ed. 47, 1946-1950 (2008).

${ }^{6}$ Z.-C. Wang, T. Weiske, R. Kretschmer, M. Schlangen, M. Kaupp, and H. Schwarz, J. Am. Chem. Soc. 133, 16930-16937 (2011).
}

${ }^{7}$ L.-H. Tian, T.-M. Ma, X.-N. Li, and S.-G. He, Dalton Trans. 42, 11205-11211 (2013).

${ }^{8}$ I. Cherchneff and E. Dwek, Astronom. J. 713, 1-24 (2010).

${ }^{9}$ J. R. Scott, G. S. Groenewold, A. K. Gianotto, M. T. Benson, and J. B. Wright, J. Phys. Chem. A 104, 7079-7090 (2000).

${ }^{10}$ G. E. Johnson, E. C. Tyo, and A. W. Castleman, Jr., J. Phys. Chem. A 112, 4732-4735 (2008)

${ }^{11}$ R. Kretschmer, Z.-C. Wang, M. Schlangen, and H. Schwarz, Angew. Chem., Int. Ed. 52, 9513-9517 (2013).

${ }^{12}$ S. B. H. Bach and S. W. McElvany, J. Phys. Chem. 95, 9091-9094 (1991).

${ }^{13}$ L. V. Serebrennikov, S. B. Osin, and A. A. Maltsev, J. Mol. Struct. 81, 25-33 (1982).

${ }^{14}$ S. M. Sonchik, L. Andrews, and K. D. Carlson, J. Phys. Chem. 87, 2004-2011 (1983).

${ }^{15}$ S. J. Bares, M. Haak, and J. W. Nibler, J. Chem. Phys. 82, 670-675 (1985).

${ }^{16}$ G. Stößer and H. Schnöckel, Angew. Chem., Int. Ed. 44, 4261-4264 (2005).

${ }^{17}$ S. R. Desai, H. Wu, and L.-S. Wang, Int. J. Mass Spectrom. 159, 75-80 (1996).

${ }^{18}$ S. R. Desai, H. Wu, C. M. Rohlfing, and L.-S. Wang, J. Chem. Phys. 106, 1309-1317 (1997)

${ }^{19}$ G. Meloni, M. J. Ferguson, and D. M. Neumark, Phys. Chem. Chem. Phys. 5, 4073-4079 (2003).

${ }^{20}$ F. A. Akin and C. C. Jarrold, J. Chem. Phys. 118, 5841-5851 (2003).

${ }^{21}$ M. Sierka, J. Döbler, J. Sauer, H. J. Zhai, and L. S. Wang, ChemPhysChem 10, 2410-2413 (2009).

${ }^{22}$ K. J. Mascaritolo, A. M. Gardner, and M. C. Heaven, J. Chem. Phys. 143, 114311 (2015).

${ }^{23}$ G. Santambrogio, E. Janssens, S. Li, T. Siebert, G. Meijer, K. R. Asmis, J. Döbler, M. Sierka, and J. Sauer, J. Am. Chem. Soc. 130, 15143-15149 (2008).

${ }^{24}$ E. F. Archibong and A. St-Amant, J. Phys. Chem. A 102, 6877-6882 (1998).

${ }^{25}$ E. F. Archibong and A. St-Amant, J. Phys. Chem. A 103, 1109-1114 (1999).

${ }^{26}$ G. L. Gutsev, P. Jena, and R. J. Bartlett, J. Chem. Phys. 110, 2928-2935 (1999).

${ }^{27}$ A. Martínez, F. J. Tenorio, and J. V. Ortiz, J. Phys. Chem. A 105, 11291-11294 (2001).

${ }^{28}$ A. B. C. Patzer, C. Chang, E. Sedlmayr, and D. Sülzle, Eur. Phys. J. D 32, 329-337 (2005).

${ }^{29}$ A. V. Nemukhin and J. Almlof, J. Mol. Struct.: THEOCHEM 85, 101-107 (1992).

${ }^{30}$ A. V. Nemukhin and F. Weinhold, J. Chem. Phys. 97, 3420-3430 (1992).

${ }^{31}$ A. B. C. Patzer, C. Chang, E. Sedlmayr, and D. Sülzle, Eur. Phys. J. D 6, 57-62 (1999).

${ }^{32}$ S. Neukermans, N. Veldeman, E. Janssens, P. Lievens, Z. Chen, and P. v. R. Schleyer, Eur. Phys. J. D 45, 301-308 (2007).

${ }^{33}$ S. M. Woodley, Proc. R. Soc. A 467, 2020-2042 (2011).

${ }^{34}$ A. B. Rahane, M. D. Deshpande, and V. Kumar, J. Phys. Chem. C 115, 18111-18121 (2011).

${ }^{35}$ M. I. M. Sarker, C. S. Kim, and C. H. Choi, Chem. Phys. Lett. 411, 297-301 (2005).

${ }^{36}$ E. F. Archibong, N. Seeburrun, and P. Ramasami, Chem. Phys. Lett. 481, 169-172 (2009).

${ }^{37}$ G. L. Gutsev, C. A. Weatherford, K. Pradhan, and P. Jena, J. Comput. Chem. 32, 2974-2982 (2011).

${ }^{38}$ D. J. Goebbert, E. Garand, T. Wende, R. Bergmann, G. Meijer, K. R. Asmis, and D. M. Neumark, J. Phys. Chem. A 113, 7584-7592 (2009).

${ }^{39}$ I. M. Goldby, B. von Issendorff, L. Kuipers, and R. E. Palmer, Rev. Sci. Instrum. 68, 3327-3334 (1997).

${ }^{40}$ See supplementary material at http://dx.doi.org/10.1063/1.4954158 for additional experimental (mass spectrum, effect of mutiple messenger tags) and computational (total energies and structures) results.

${ }^{41}$ W. Schöllkopf, S. Gewinner, H. Junkes, A. Paarmann, G. von Helden, H. Bluem, and A. M. M. Todd, Proc. SPIE 9512, 95121L (2015).

${ }^{42}$ N. Heine and K. R. Asmis, Int. Rev. Phys. Chem. 34, 1-34 (2015).

${ }^{43}$ M. Sierka, Prog. Surf. Sci. 85, 398-434 (2010).

${ }^{44}$ M. Sierka, J. Döbler, J. Sauer, G. Santambrogio, M. Brümmer, L. Wöste, E. Janssens, G. Meijer, and K. R. Asmis, Angew. Chem., Int. Ed. 46, 3372-3375 (2007).

${ }^{45}$ J. P. Perdew, Phys. Rev. B 33, 8822-8824 (1986).

${ }^{46}$ A. D. Becke, Phys. Rev. A 38, 3098-3100 (1988).

${ }^{47}$ F. Weigend and R. Ahlrichs, Phys. Chem. Chem. Phys. 7, 3297-3305 (2005).

${ }^{48}$ A. D. Becke, J. Chem. Phys. 98, 5648 (1993).

${ }^{49}$ TURBOMOLE V6.5 2013, a development of University of Karlsruhe and Forschungszentrum Karlsruhe GmbH, 1989-2007, TURBOMOLE GmbH, since 2007; available from http://www.turbomole.com. 
${ }^{50}$ A. D. Becke, J. Chem. Phys. 98, 1372 (1993).

${ }^{51}$ K. Raghavachari, G. W. Trucks, J. A. Pople, and M. Head-Gordon, Chem. Phys. Lett. 157, 479-483 (1989).

${ }^{52}$ K. A. Peterson and T. H. Dunning, J. Chem. Phys. 117, 10548 (2002).

${ }^{53}$ M. Sierka, B. Helmich, and R. Wlodarczyk, Program DoDo (Humboldt University Berlin, Friedrich-Schiller University Jena, 2013).

${ }^{54}$ V. Barone, J. Chem. Phys. 122, 14108 (2005).

${ }^{55}$ H.-J. Werner, P. J. Knowles, G. Knizia, F. R. Manby, and M. Schütz, Wiley Interdiscip. Rev.: Comput. Mol. Sci. 2, 242-253 (2012).

${ }^{56}$ M. J. Frisch, G. W. Trucks, H. B. Schlegel, G. E. Scuseria, M. A. Robb, J. R. Cheeseman, G. Scalmani, V. Barone, B. Mennucci, G. A. Petersson, H. Nakatsuji, M. Caricato, X. Li, H. P. Hratchian, A. F. Izmaylov, J. Bloino, G. Zheng, J. L. Sonnenberg, M. Hada, M. Ehara, K. Toyota, R. Fukuda, J. Hasegawa, M. Ishida, T. Nakajima, Y. Honda, O. Kitao, H. Nakai, T. Vreven, J. A. Montgomery, Jr., J. E. Peralta, F. Ogliaro, M. Bearpark, J. J. Heyd, E. Brothers, K. N. Kudin, V. N. Staroverov, R. Kobayashi, J. Normand, K. Raghavachari, A. Rendell, J. C. Burant, S. S. Iyengar, J. Tomasi, M. Cossi, N. Rega, J. M. Millam, M. Klene, J. E. Knox, J. B. Cross, V. Bakken, C. Adamo, J. Jaramillo, R. Gomperts, R. E. Stratmann, O. Yazyev, A. J. Austin, R. Cammi, C. Pomelli, J. W. Ochterski, R. L. Martin, K. Morokuma, V. G. Zakrzewski, G. A. Voth, P. Salvador, J. J. Dannenberg, S. Dapprich, A. D. Daniels, Ö. Farkas, J. B. Foresman, J. V. Ortiz, J. Cioslowski, and D. J. Fox, GaUsSIAN 09, Gaussian, Inc., Wallingford CT, 2009.

${ }^{57}$ L. Andrews and M. McCluskey, J. Mol. Spectrosc. 154, 223-225 (1992).

${ }^{58}$ S. Gowtham, A. Costales, and R. Pandey, J. Phys. Chem. B 108, 17295-17300 (2004).
${ }^{59}$ H.-J. Zhai, L.-M. Wang, S.-D. Li, and L.-S. Wang, J. Phys. Chem. A 111, 1030-1035 (2007).

${ }^{60}$ B. Tremblay, P. Roy, L. Manceron, M. E. 1. Alikhani, and D. Roy, J. Chem. Phys. 104, 2773 (1996).

${ }^{61}$ A. Beste and R. J. Bartlett, Chem. Phys. Lett. 366, 100-108 (2002).

${ }^{62}$ S. Gowtham, M. Deshpande, A. Costales, and R. Pandey, J. Phys. Chem. B 109, 14836-14844 (2005)

${ }^{63}$ E. F. Archibong and P. Ramasami, Comput. Theor. Chem. 964, 324-328 (2011).

${ }^{64}$ P. V. Avramov, I. Adamovic, K.-M. Ho, C. Z. Wang, W. C. Lu, and M. S. Gordon, J. Phys. Chem. A 109, 6294-6302 (2005).

${ }^{65}$ A. B. Rahane and M. D. Deshpande, J. Phys. Chem. C 116, 2691-2701 (2012).

${ }^{66}$ A. K. Kandalam, B. Kiran, P. Jena, S. Pietsch, and G. Ganteför, Phys. Chem. Chem. Phys. 17, 26589-26593 (2015).

${ }^{67}$ E. F. Archibong and E. N. Mvula, Chem. Phys. Lett. 408, 371-376 (2005).

${ }^{68}$ K. R. Asmis, G. Meijer, M. Brümmer, C. Kaposta, G. Santambrogio, L. Wöste, and J. Sauer, J. Chem. Phys. 120, 6461-6470 (2004).

${ }^{69} \mathrm{M}$. Sodupe, J. Bertran, L. Rodriguez-Santiago, and E. J. Baerends, J. Phys. Chem. A 103, 166-170 (1999).

${ }^{70}$ K. R. Asmis, G. Santambrogio, M. Brümmer, and J. Sauer, Angew. Chem., Int. Ed. 44, 3122-3125 (2005).

${ }^{71}$ G. Pacchioni, F. Frigoli, D. Ricci, and J. A. Weil, Phys. Rev. B 63, 054102 (2001).

${ }^{72}$ X. Solans-Monfort, V. Branchadell, M. Sodupe, M. Sierka, and J. SauerJ. Chem. Phys. 121, 6034-6041 (2004).

${ }^{73}$ J. P. Merrick, D. Moran, and L. Radom, J. Phys. Chem. A 111, 11683-11700 (2007). 